\title{
A Disposable Electrochemical Glucose Sensor Using Catalytic Subunit of Novel Thermostable Glucose Dehydrogenase
}

\author{
Hideaki Yamaoka and Koji Sode* \\ Department of Biotechnology, Graduate School of Engineering Tokyo University of Agriculture and Technology, 2-24- \\ 16 Naka-cho, Koganei, Tokyo, 184-8588, Japan
}

\begin{abstract}
We report here the development of a novel disposable-type glucose enzyme sensor based on a screen-printed carbon electrode (SPCE) employing a catalytic subunit of FAD-dependent glucose dehydrogenase (FADGDH) and a Rucomplex (hexaammineruthenium (III) chloride) as the electron mediator. The whole blood glucose measurement was achieved in 2 seconds using a $500 \mathrm{nl}$ sample of the range of $100-800 \mathrm{mg} / \mathrm{ml}$.
\end{abstract}

Keywords: Self monitoring of blood glucose, glucose sensor, glucose dehydrogenase, screen printed carbon electrode, Rucomplex.

\section{INTRODUCTION}

With the increase in the number of diabetes patients, much attention is paid to the precise monitoring of the daily blood glucose, and especially to self-monitoring by the patients themselves, a process known as the "self-monitoring of blood glucose" (SMBG).(Anonymous ADC 1985) [1] (Cava AP 1999) [2] (Ikeda DRCP 1994) [3]. Currently available sensing systems for SMBG all employ enzymes, either glucose oxidase (GOD) or glucose dehydrogenase (GDH). (D'Costa Biosensors 1986) [4]. Because GDH-harboring pyrroloquinoline quinone (PQQ) does not rely on oxygen as its electron acceptor, PQQGDH is now widely used as the enzyme for artificial electron mediator-based electrochemical glucose sensing systems. (Kost CCM 1998) [5] (Feldman DTT 2000) [6]. However, no researcher has ever reported on the use of thermostable cofactor binding-type GDH, which may allow a longer shelf life and easier handling during the sensor fabrication process.

The authors have been engaged in the development of an ideal enzyme for glucose monitoring, through protein engineering and the screening of enzymes from natural sources. We have previously reported on a novel membrane-bound thermostable periplasmic GDH from Burkhorderia. cepacia (Sode EMT 1996) [7]. The GDH purified from B. cepacia is a flavoprotein consisting of three nonidentical subunits: a catalytic subunit containing FAD, a cytochrome $c$ subunit as the electron transfer subunit, and a small subunit with unknown function. Interestingly, the catalytic subunit alone shows dye-mediated GDH activity; its activity can be maintained even at $70^{\circ} \mathrm{C}$, and it is stable even after incubation at $70^{\circ} \mathrm{C}$ in a buffer solution for more than 30 minutes (Yamazaki ABB 1999) [8]. We recently reported on the recombinant preparation of the catalytic subunit, which allows us to prepare a quantity of enzyme sufficient to meet the needs of the SMBG market (Inose BBA 2003) [9] (Yamaoka BL 2004) [10]. The properties of this new thermostable GDH, FADGDH, inspired us to construct a disposable-type enzyme

*Address correspondence to this author at the Department of Biotechnology, Graduate School of Engineering Tokyo University of Agriculture and Technology, 2-24-16 Naka-cho, Koganei, Tokyo, 184-8588, Japan; E-mail: sode@cc.tuat.ac.jp electrode, combined with a cost-effective screen-printed electrode (SPCE), which may enable the production of a rapid, sensitive and even durable glucose sensor suitable for SMBG.

For the enzyme sensors employing PQQGDH, potassium ferricyanide is frequently used as the electron carrier (Kost CCM 1998) [5]. Potassium ferricyanide is a good mediator for glucose sensors due to its cost efficiency and electron transfer ability. However, potassium ferricyanide is a lightsensitive material which needs to be kept away from light when the sensor is being fabricated or stored. Ivanova studied the potential application of the Ru-complex as the electron mediator for PQQGDH using the amperometric method. The $\mathrm{Ru}(\mathrm{III})$ complex exhibited a high catalytic activity in the reaction with PQQGDH. The reaction was of the first kinetic order for the enzyme (Ivanova BM 2003) [11].

In this paper, we report a novel disposable amperometric glucose sensor employing a thermostable FADGDH catalytic subunit, a Ru-complex as the mediator, and an SPCE. We evaluate the potential application of this new enzyme mediator-based glucose sensor to blood glucose monitoring.

\section{MATERIAL AND METHODS}

\section{Reagents}

The catalytic subunit of FADGDH (1200 U/mg) was purified form recombinant $E$. coli, as described previously (Inose BBA 2003) [7]. Potassium ferricyanide, hexaammineruthenium(III) chloride, N-(2-Acetamido)-2-aminoethanesulfonic acid (ACES) and 3-[(3-Cholamidopropyl) dimethylammonio]-1-propanesulfonate (CHAPS) were purchased from Dojin Chemical (Japan). D-Glucose was purchased from Nacalai Tesque (Japan). The biological samples were prepared form human venous whole blood. Blood was collected into a heparin-Na vacuum blood collection tube $(5 \mathrm{ml})$ and the hematocrit was brought to $42 \%$.

The blood samples used for the evaluation were turned upside down and agitated to prevent hemolysis, and a glucose solution was added in order to adjust the glucose concentration. The concentration of glucose was checked using a standard glucose analyzer (GA-1150, Arkray Inc., Japan). 


\section{Electrode Preparation}

Modification of the electrode with an enzyme and mediator is described below. One $\mu \mathrm{l}$ of mediator solution containing $200 \mathrm{mM}$ ACES (pH 7.0), 0.1\% CHAPS and $60 \mathrm{mM}, 120$ $\mathrm{mM}$ or $240 \mathrm{mM}$ potassium ferricyanide or hexaammineruthenium(III) chloride were dropped onto the SPCE (60 $\mathrm{nmol}, 120 \mathrm{nmol}$ or $240 \mathrm{nmol} / \mathrm{sensor}$ ) and dried at $30^{\circ} \mathrm{C}$ for 30 seconds to produce a mediator-covered SPCE. Then, 0.5 $\mu 1$ of $1600 \mathrm{U} / \mathrm{ml}, 3200 \mathrm{U} / \mathrm{ml}, 4800 \mathrm{U} / \mathrm{ml}$ or $9600 \mathrm{U} / \mathrm{ml}$ of FADGDH solution containing $0.1 \%$ CHAPS was dropped onto the mediator layer on the SPCE $(0.8 \mathrm{U}, 1.6 \mathrm{U}, 2.4 \mathrm{U}$ or $4.8 \mathrm{U} /$ sensor) and dried at $30^{\circ} \mathrm{C}$ for 30 seconds for the deposit to form.

\section{Electrochemical Measurement}

We used a single-potential time base (TB) to measure the glucose in the blood samples. A potential of $+200 \mathrm{mV} v s$ the counter electrode was applied immediately when the capillary became filled with the sample. Then, the catalytic current was monitored. Calibration plots were obtained by sampling the current values at 2, 5 or 10 seconds. A calibration curve was generated based on the average of 5 measurements for each glucose concentration.

The FADGDH sensors with either the Ru-complex or potassium ferricyanide were exposed to fluorescent lamp light at 50,000 lux for 4 days at $25^{\circ} \mathrm{C}$. After the light exposure, the sensor responses were tested on a blood sample containing $0 \mathrm{mg} / \mathrm{dl}$ glucose using a 2 -second measurement.

The thermal stability of the sensor with the Ru-complex was evaluated after exposure at $40^{\circ} \mathrm{C}$ under $80 \%$ relative humidity (Rh), or at $30^{\circ} \mathrm{C}$ under $80 \% \mathrm{Rh}$ for 24 hours to evaluate the thermal stability. After the exposure, the sensor response was tested using a blood sample containing 600 $\mathrm{mg} / \mathrm{dl}$ glucose. All measurements were performed at room temperature $\left(25^{\circ} \mathrm{C}\right)$.

\section{RESULTS AND DISCUSSION}

\section{SPCE Electrode}

Considering that the current requirement in the SMBG market is cost-efficiency, we adopted a screen-printed carbon electrode (SPCE). SPCEs can be mass-produced and are simple to use.

The schematic layout of SPCE is shown in Fig. (1a,b).

The structure of the sensor (Fig. 1a) and the overview of finished sensor (Fig. 1b) are shown. The upper carbon layer is the working electrode and the lower carbon electrode is the counter electrode. The green part is the insulate print with $25 \mu \mathrm{m}$, which defines the reagent dipping zone. Double faced tape with $60 \mu \mathrm{m}$ in thickness is used as the make of capillary space attaching the cover by base film.

The first and second electrodes are formed on the substrate by screen printing with a carbon paste. Then, insulation printing is performed in order to create a reagent dipping zone in the thickness of $25 \mu \mathrm{m}$. Double-face tape and base film are used to create a capillary to conduct the sample to the electrode. The size of the working electrode and the counter electrode is $1 \mathrm{~mm} \times 1 \mathrm{~mm}$. The sample volume of the sensor is $500 \mathrm{nl}(\mathrm{W} \times \mathrm{L} \times \mathrm{H}=6 \mathrm{~mm} \times 1 \mathrm{~mm} \times 0.085 \mathrm{~mm})$, which was adjusted by using insulating print $(25 \mu \mathrm{m})$ and doubleface tape $(60 \mu \mathrm{m})$
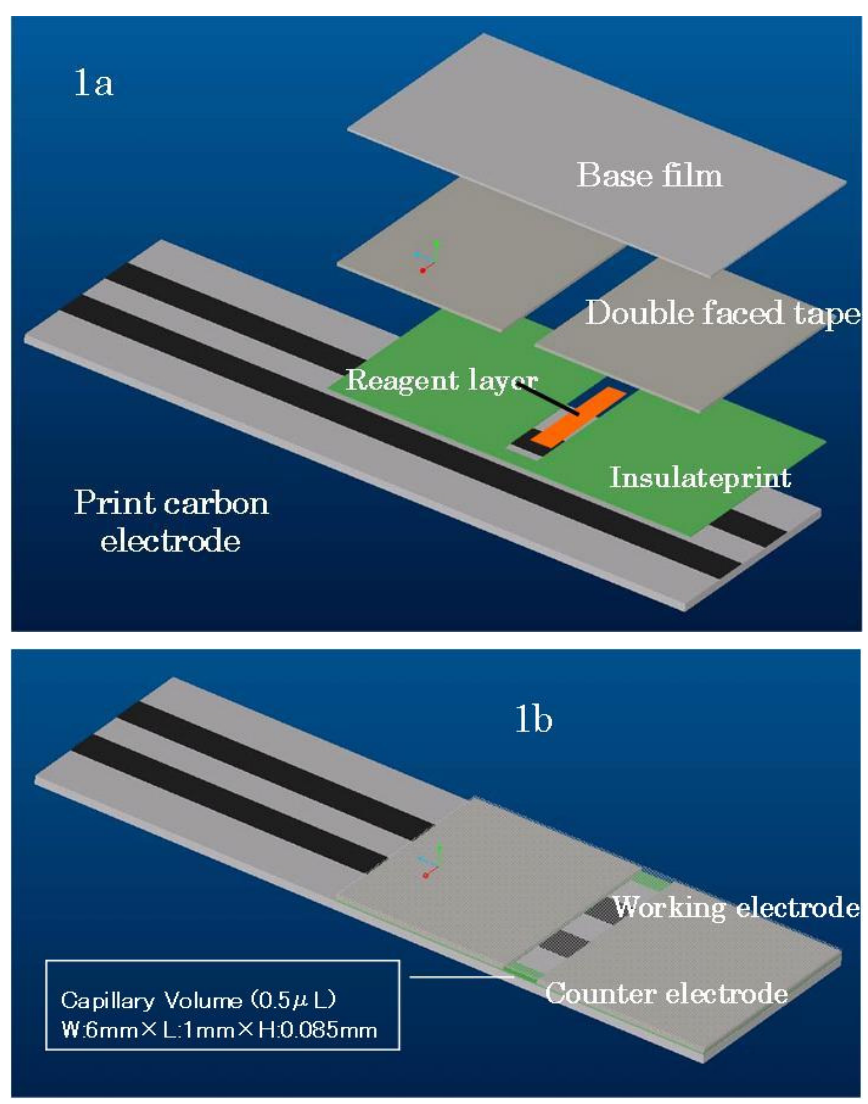

Fig. (1). Schematic diagram of the sensor.

\section{Optimization of Sensor Components}

First, we investigated the amount of enzyme immobilized on the SPCE. In order to ensure the correct measurement of glucose in whole blood, the enzyme sensor response was analyzed by the chronoamperometric method. The singlepotential time base (TB) was obtained from the whole blood samples. As shown in Fig. (2a-d), the current peak was reached in about 0.5 seconds, after which the current gradually decreased. The current after 5 seconds was plotted against glucose concentration.

Glucose concentration was $0 \mathrm{mg} / \mathrm{dl}, 230 \mathrm{mg} / \mathrm{dl}, 398$ $\mathrm{mg} / \mathrm{dl}, 590 \mathrm{mg} / \mathrm{dl}$, respectively.

Fig. (3) shows the correlation between the glucose concentration and the sensor current observed after 5 seconds with different amounts of enzyme. A good linear correlation was observed between the glucose concentration and the current at each time point of measurement within the glucose concentration range tested in this study, 0-600 mg/dl.

The current responses from single potential time base (TB) of the sensor with various glucose concentrations in whole blood sample after 5 seconds were plotted. Glucose concentration was $0 \mathrm{mg} / \mathrm{dl}, 230 \mathrm{mg} / \mathrm{dl}, 398 \mathrm{mg} / \mathrm{dl}, 590$ $\mathrm{mg} / \mathrm{dl}$, respectively. The error bar was calculate as a standard deviation of measurement of $n=3$

The amount of enzyme immobilized on the SPCE affected the dynamic range of the sensor. With lower amounts 

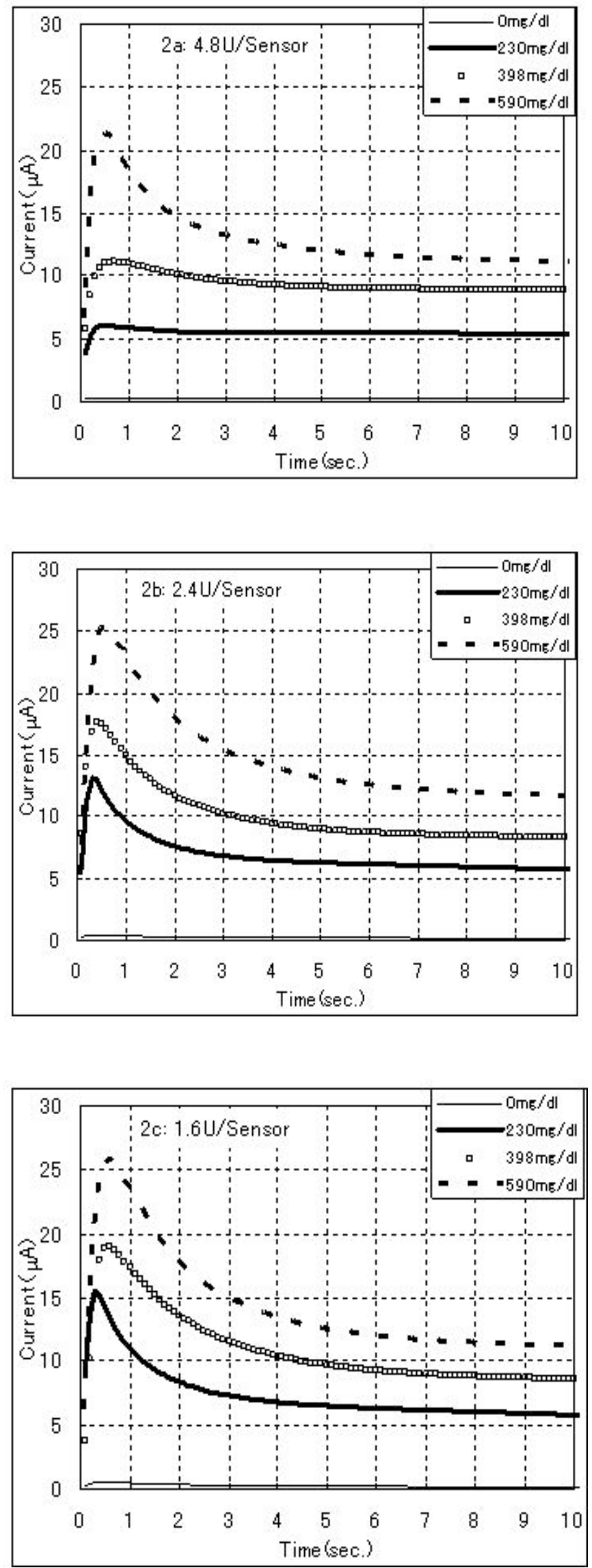

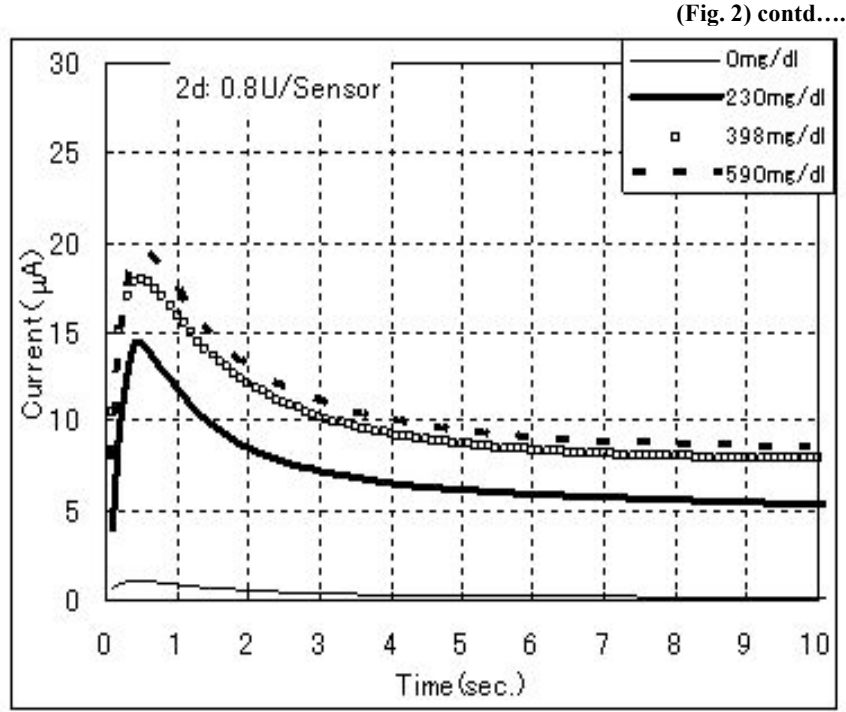

Fig. (2). Time Base of FADGDH/Ru-complex dipped SPCE with different amount of enzyme a; $4.8 \mathrm{U} /$ sensor, $\mathbf{b} ; 2.4 \mathrm{U} /$ sensor, $\mathbf{c} ; 1.6$ $\mathrm{U} /$ sensor, $\mathbf{d}$; $0.8 \mathrm{U} /$ sensor.

of enzyme ( $0.8 \mathrm{U}, 1.6 \mathrm{U} / \mathrm{sensor})$, the sensor responses seem not enough for measuring glucose concentrations in accuracy, higher than $400 \mathrm{mg} / \mathrm{dl}$. Because of standard deviation (S.D) was larger than $2.4 \mathrm{U} /$ sensor and $4.8 \mathrm{U} /$ sensor. With higher amounts of enzyme (2.4 $\mathrm{U}$ and $4.8 \mathrm{U} /$ sensor), seem enough for measurement of $600 \mathrm{mg} / \mathrm{dl}$. There were no difference between $2.4 \mathrm{U} /$ sensor and $4.8 \mathrm{U} /$ sensor of current and S.D, we thereafter immobilized 2.4 U FADGDH per sensor, think for cost of sensor.

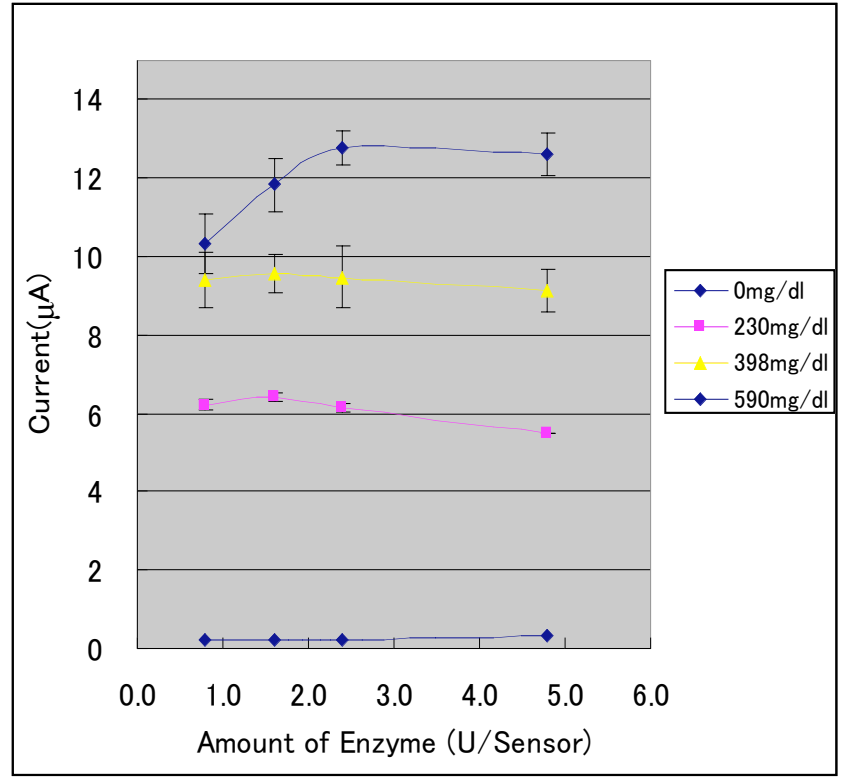

Fig. (3). Current of the different amount of enzyme, for different values of the glucose concentration.

The current responses from single potential time base (TB) of the sensor with various glucose concentrations in whole blood sample after 5 seconds were plotted. Glucose concentration was $0 \mathrm{mg} / \mathrm{dl}, 101 \mathrm{mg} / \mathrm{dl}, 412 \mathrm{mg} / \mathrm{dl}, 624$ $\mathrm{mg} / \mathrm{dl}$, respectively. The error bar was calculate as a standard deviation of measurement of $n=3$. 


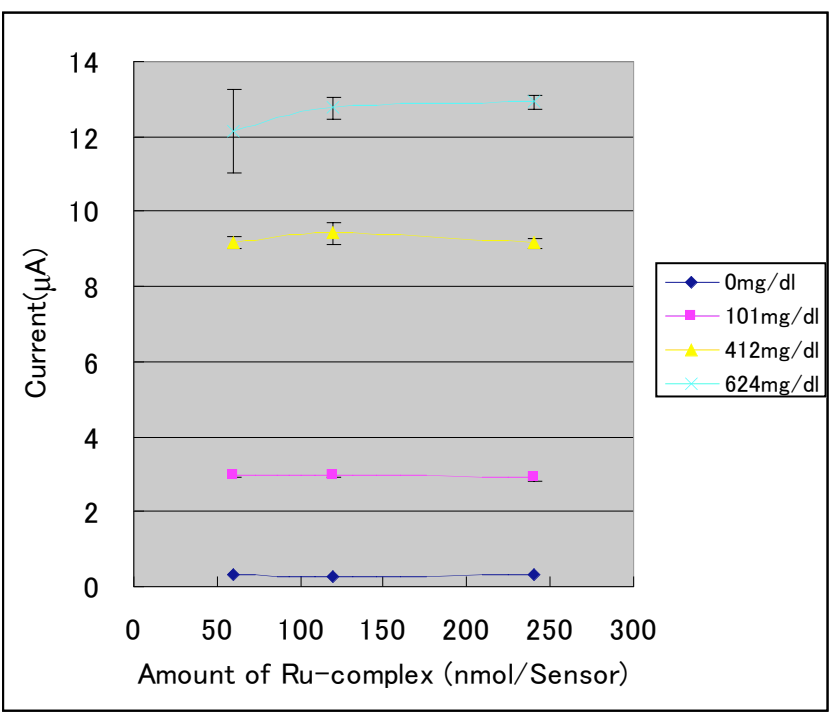

Fig. (4). Current of the different amount of Ru-complex, (60 nmol, $120 \mathrm{nmol}$ or $240 \mathrm{nmol}$ ) for different values of the glucose concentration.

Similarly, the amount of Ru-complex mediator immobilized on the sensor was investigated using SPEC with $2.4 \mathrm{U}$ FADGDH per sensor (Fig. 4). There were no differences between three amounts type of the response until $412 \mathrm{mg} / \mathrm{dl}$ of glucose. But in glucose concentration of $624 \mathrm{mg} / \mathrm{dl}, 60$ $\mathrm{nmol} / \mathrm{sensor}$ was inferior of current out put and S.D.

Fig. (4) suggested that among the $\mathrm{Ru}$ amount/sensor we tested, the configuration with $120 \mathrm{nmol}$ or $240 \mathrm{nmol} \mathrm{Ru}$ complex per sensor, resulted in the measurement with high accuracy, and no significant difference in their performances are observed. Considering the bulky price of electron mediator and its instability, we chose the highest $\mathrm{Ru}$ amount/sensor, $240 \mathrm{nmol} / \mathrm{sensor}$, as the quantity of the electron mediator.

\section{Sensor Operation and Evaluation}

Since a short period of analysis is preferable in commercially available SMBG systems, we then investigated the sampling time for the measurements.

Plotted current response from single potential time base (TB) of the sensor with various glucose concentrations in whole blood sample after 2, 5, 10 seconds. Glucose concentration was $0 \mathrm{mg} / \mathrm{dl}, 101 \mathrm{mg} / \mathrm{dl}, 412 \mathrm{mg} / \mathrm{dl}, 624 \mathrm{mg} / \mathrm{dl}, 820$ $\mathrm{mg} / \mathrm{dl}$ respectively. The error bar was calculate as a standard deviation of measurement of $n=5$

Fig. (5) shows the calibration curve obtained with various sampling times ( $2 \mathrm{sec}, 5 \mathrm{sec}$ or $10 \mathrm{sec})$ and various concentrations of glucose in the blood sample (240 nmol Rucomplex and 2.4 U FADGDH per sensor). As a result, good linear correlations were observed for the three different sampling times between the sensor signals and the blood glucose concentration within the examined range $(0-800 \mathrm{mg} / \mathrm{dl}$ whole blood glucose concentration).

We then evaluated the correlation coefficient of the sensor for each sampling time. With all sampling times, the sensor showed good correlations: $\mathrm{r}=0.9998$ for 2 seconds of measurement, $\mathrm{r}=0.9991$ for 5 seconds of measurement, and $r=0.9989$ for 10 seconds of measurement. These correlation coefficient value will meat the ISO 15197 standard of $\mathrm{r}>0.98$.

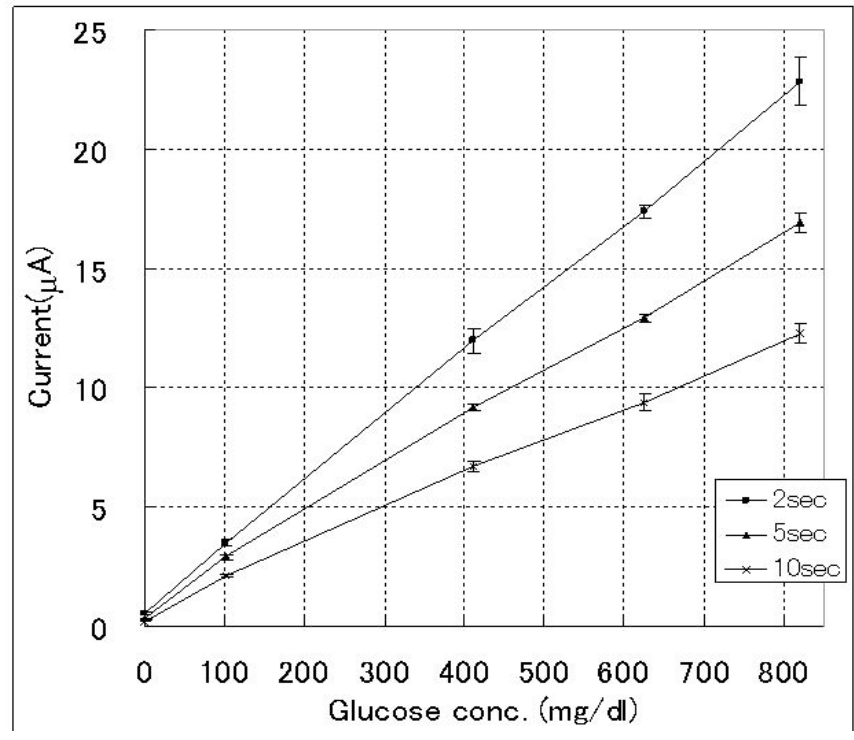

Fig. (5). Calibration curves of the finished sensors with whole blood glucose with different sampling time ( $2 \mathrm{sec}, 5 \mathrm{sec}$, or $10 \mathrm{sec}$ ), with the $240 \mathrm{nmol} \mathrm{Ru}$ and 2.4 U FADGDH dipped SPCE.

Table 1. Coefficient Variation (C.V.) of Measurement

\begin{tabular}{|c|c|c|c|c|c|}
\hline & $\mathbf{0}$ & $\mathbf{1 0 1}$ & $\mathbf{4 1 2}$ & $\mathbf{6 2 4}$ & $\mathbf{8 2 0} \mathbf{~ m g / d l}$ \\
\hline \hline $2 \mathrm{sec}$ & $12.9 \%$ & $4.5 \%$ & $4.2 \%$ & $1.7 \%$ & $4.4 \%$ \\
\hline $5 \mathrm{sec}$ & $9.4 \%$ & $3.5 \%$ & $1.5 \%$ & $1.3 \%$ & $2.5 \%$ \\
\hline $10 \mathrm{sec}$ & $10.0 \%$ & $3.2 \%$ & $2.9 \%$ & $3.7 \%$ & $3.5 \%$ \\
\hline
\end{tabular}

Table 1 shows the reproducibility of the sensors $(n=5)$. All sampling times achieved good reproducibility; the 2second measurement had a CV value of $1.7-4.5 \%$, the 5second measurement a CV value of $1.3-3.5 \%$, and the 10 second measurement a CV value of $2.9-3.7 \%$. These C.V value will meat the ISO 15197 standard of $\mathrm{CV}<4.5 \%$. These results indicate that the SPCE employing the FADGDH catalytic subunit and the Ru-complex as the electron mediator has high precision and reproducibility, and that measurement can be achieved in 2 seconds using a $500 \mathrm{nl}$ of whole blood sample.

\section{Sensor Stability}

In Table 2, the stability of the sensor toward light exposure is summarized for SPCE employing either the Rucomplex or the potassium ferricyanide as the electron mediator, immobilized together with the FADGDH catalytic subunit.

Table 2. Light Exposure Stability

\begin{tabular}{|c|c|c|}
\hline & $\mathbf{0 l u x}$ & $\mathbf{5 0 , 0 0 0 l u x}$ \\
\hline \hline Ru-complex & $0.17 \mu \mathrm{A}$ & $0.18 \mu \mathrm{A}$ \\
\hline Ferricyanide & $1.78 \mu \mathrm{A}$ & $9.10 \mu \mathrm{A}$ \\
\hline
\end{tabular}


The sensor responses toward blood samples without glucose were compared before and after a 4-day exposure to 50,000 lux of fluorescent light. The sensor with the Rucomplex as the electron mediator showed no change in the current for the blood sample without glucose, which indicates a stable background signal. However, the sensor with potassium ferricyanide as the electron mediator showed an increase in the background current of about 7 compared with the current before the light exposure. Thus, the increase in the background current corresponded to the signal for the sample containing $200 \mathrm{mg} / \mathrm{dl}$ of glucose. Stability toward light exposure contributes to the easiness of manufacturing and storage; therefore, the Ru-complex is preferable to potassium ferricyanide as the electron mediator for the sensor.

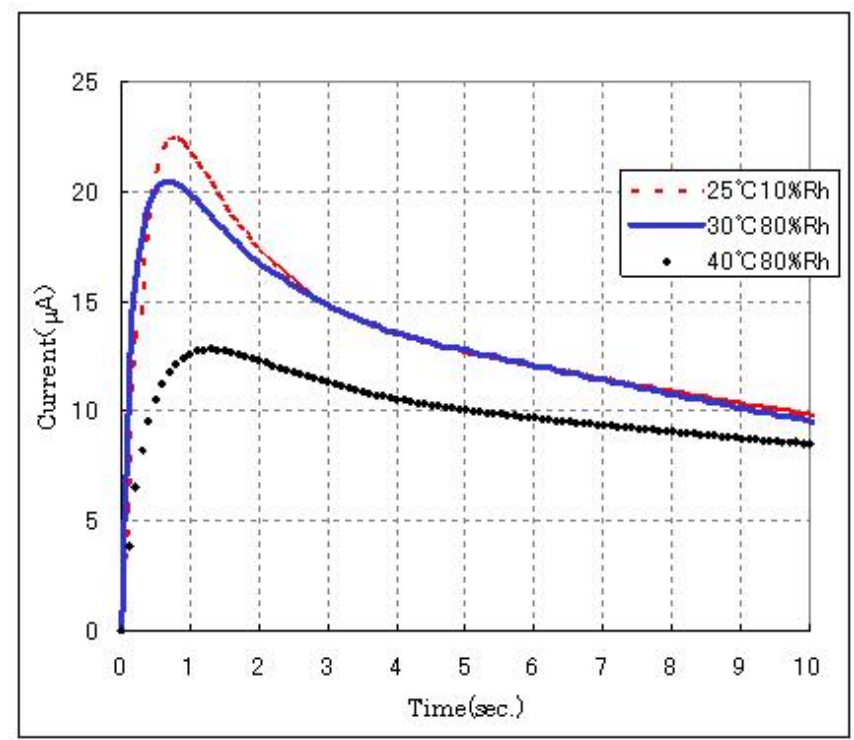

Fig. (6). Thermal stability of the sensor.

The effect of temperature and humidity on stability was investigated. Sensors were kept at either $25^{\circ} \mathrm{C} 10 \% \mathrm{Rh}, 30^{\circ} \mathrm{C}$ $80 \% \mathrm{Rh}, 40^{\circ} \mathrm{C} 80 \% \mathrm{Rh}$. After 24 hours of incubation, the sensors were used to measure the glucose in whole blood samples with a glucose concentration of $600 \mathrm{mg} / \mathrm{dl}$. The stability was estimated from the bias from the results given by sensors kept at $25^{\circ} \mathrm{C} 10 \% \mathrm{Rh}$.

The thermal stability of the SPCE with the FADGDH catalytic subunit and the Ru-complex was then investigated. Fig. (6) shows the time course of the reaction during the measurement of the whole blood glucose concentration after incubation of the sensor at $40^{\circ} \mathrm{C}, 80 \% \mathrm{Rh}$ and at $30^{\circ} \mathrm{C}, 80 \%$ $\mathrm{Rh}$ for 24 hours. As can be seen in Fig. (6), the sensor remained almost intact after 24 hours of incubation at $30^{\circ} \mathrm{C}$, $80 \% \mathrm{Rh}$. Even after incubation at $40^{\circ} \mathrm{C}, 80 \% \mathrm{Rh}$ for 24 hours, the sensor generated more than $80 \%$ of the signal compared with the initial condition. These results suggest that the
SPCE electrode with the FADGDH catalytic subunit and the Ru-complex has thermal stability.

\section{CONCLUSIONS}

In this paper, a novel disposable-type glucose enzyme sensor designed for SMBG is reported. The sensor was constructed based on SPCE employing the catalytic subunit of FADGDH and a Ru-complex as the electron mediator. Whole blood glucose measurement was achieved in 2 seconds using a $500 \mathrm{nl}$ whole blood sample, with high precision and reproducibility. Tolerance to light exposure and thermal stability were also achieved due to the inherent properties of the Ru-complex and the FADGDH catalytic subunit. These results indicate that the novel disposable-type glucose sensor reported in this study, i.e. SPCE employing a FADGDH catalytic subunit and a Ru-complex, brings great advantages to SMBG.

\section{REFERENCES}

[1] Anonymous. Self-monitoring of blood glucose. American diabetes association. Diabetes Care 1985; 8(5): 515.

[2] Cava F, Cantos E, Molina MC, Fernandez MI, Parron T, Carrillo L. The self-measurement of blood glucose and mean glycemias in patients with diabetes mellitus. Aten Primaria 1999; 23(2): 82-86.

[3] Ikeda Y, Tsuruoka A. Self-monitoring of blood glucose, as a means of self-management. Diabetes Res Clin Pract 1994; 24(Suppl) S269-71.

[4] D'Costa EJ, Higgins IJ, Turner AP. Quinoprotein glucose dehydrogenase and its application in an amperometric glucose sensor. Biosensors 1986; 2(2): 71-87.

[5] Kost GJ, Vu HT, Lee JH, et al. Multicenter study of oxygeninsensitive handheld glucose point-of-care testing in critical care/hospital/ambulatory patients in the united states and canada. Crit Care Med 1998; 26(3): 581-590.

[6] Feldman B, McGarraugh G, Heller A, Bohannon N, Skyler J, DeLeeuw E, Clarke D. FreeStyle: A small-volume electrochemical glucose sensor for home blood glucose testing. Diabet Technol Ther 2000; 2(2): 221-229.

[7] Sode K, Tsugawa W, Yamazaki T, Watanabe M, Ogasawara N, Tanaka M. A novel thermostable glucose dehydrogenase varying temperature quaternary structures. Enzyme Microbiol Thechnol 1996; 19: 82-85.

[8] Yamazaki T, Tsugawa W, Sode K. Subunit analyses of a novel thermostable glucose dehydrogenase showing different temperature properties according to its quaternary structure. Appl Biochem Biotecnol 1999; (77-99): 325-335.

[9] Inose K, Fujikawa M, Yamazaki T, Kojima K, Sode K. Cloning and expression of the gene encoding catalytic subunit of thermostable glucose dehydrogenase from burkholderia cepacia in Escherichia coli. Biochim Biophys Acta 2003; 1645(2): 133-138.

[10] Yamaoka H, Ferri S, Fujikawa M, Sode K. Essential role of the small subunit of thermostable glucose dehydrogenase from burkholderia cepacia. Biotechnol Lett 2004; 26(22): 1757-1761.

[11] Ivanova EV, Ershov AY, Laurinavicius V, Meskus R, Ryabov AD. Comparative kinetic study of D-glucose oxidation by ruthenium(III) compounds catalyzed by FAD-dependent glucose oxidase and PQQ-dependent glucose dehydrogenase. Biochemistry (Mosc) 2003; 68(4): 407-415. 